\title{
Atitude Religiosa e Sentido da Vida: Um Estudo Correlacional
}

\author{
Religious Attitude and The Meaning of Life: \\ A Correlational Study
}

Actitud Religiosa y Sentido de la Vida:

Un Estudio Correlativo

Thiago Antônio Avellar de Aquino, Amanda Pereira Moreira Correia, Ana Laura Câmara Marques, Cristiane Gabriel de Souza, Heloísa Carolina de Assis Freitas, Izabela Ferreira de Araújo, Poliana dos Santos Dias \& Wilma Fernandes de Araújo Universidade Estadual da Paraíba

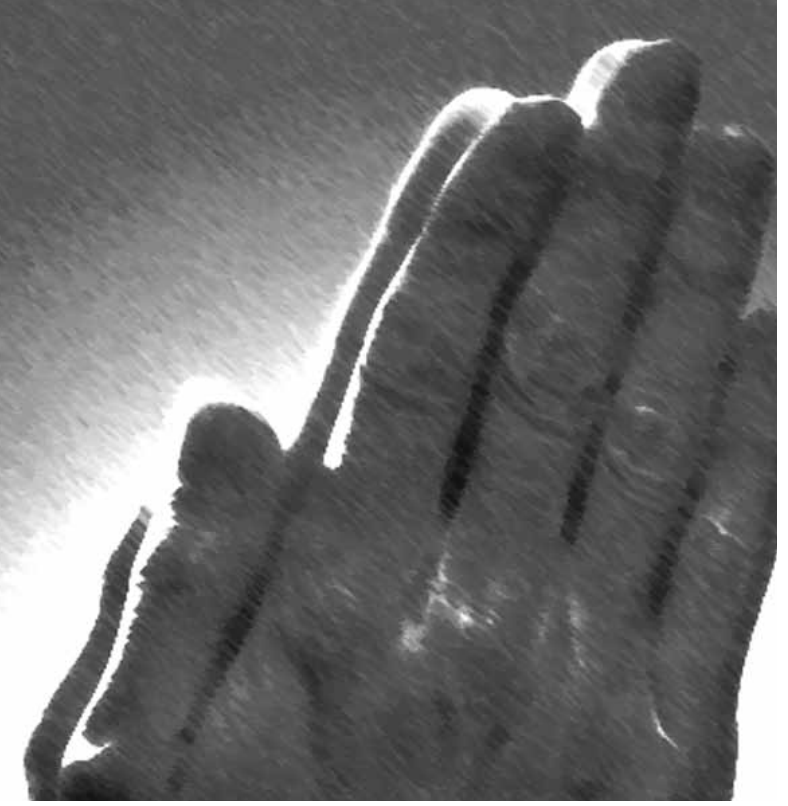


Resumo: A presente pesquisa abordou o sentido da vida (Viktor Frankl) e a atitude religiosa. Para a logoterapia, a religiosidade não significa necessariamente a opção por uma crença religiosa, mas pode ser uma das possíveis maneiras de o homem encontrar sentido para a vida. O objetivo deste estudo foi investigar a relação entre o sentido de vida e a atitude religiosa de forma transversal e correlacional. A amostra foi composta por 300 sujeitos de ambos os sexos, 37\% homens e $63 \%$ mulheres, com idade média de 42 anos. Os instrumentos utilizados foram o Teste Propósito de Vida (PIL-Test), de James C. Crumbauch e Leonard T. Maholick, e a Escala de Atitude Religiosa/Espiritualidade, de Aquino. Os resultados apontam correlações positivas entre a atitude religiosa e a realização existencial, a atitude religiosa e a idade, o desespero existencial e o vazio existencial e a realização existencial e a idade, havendo também correlações negativas entre a atitude religiosa e o desespero existencial, a atitude religiosa e o vazio existencial, o desespero existencial e a realização existencial e o vazio existencial e a realização existencial. Concluiu-se que a atitude religiosa é uma forma de encontro de sentido de vida bem como um elemento de prevenção do vazio existencial e do desespero existencial.

Palavras-chave: Sentido de vida. Atitude. Religião. Religiosidade.

Abstract: This research has investigated the meaning of life (Viktor Frankl) and the religious attitude. According to logotherapy, religiousness does not necessarily mean the choice for a specific religion, but it can be one of the possible ways for man to find the meaning in life. This study aimed at investigating the relationship between the meaning of life and the religious attitude in a transversal and correlational manner. The sample was composed of 300 participants, male and female. 37\% men and 63\% women, 42 years old average. The instruments were Crumbauch and Maholick's Life Purpose Test (PIL-Test) and Aquino's Religiousness/ Spirituality Attitude Scale. The results showed positive correlations between religious attitude and existential realization, religious attitude and age, existential despair and existential emptiness, and existential realization and age, as well as negative correlations between religious attitude and existential despair, religious attitude and existential emptiness, existential despair and existential realization, and existential emptiness and existential realization. It was observed that the religious attitude is a way to find the meaning of life, as well as an element to avoid existential emptiness and existential despair.

Keywords: Meaning of life. Attitude. Religion. Religiosity.

Resumen: La presente pesquisa abordó el sentido de la vida (Viktor Frankl) y la aptitud religiosa. Para la logoterapia, la religiosidad no significa necesariamente la opción por una creencia religiosa, pero puede ser una de las posibles maneras del hombre de encontrar sentido para la vida. El objetivo de este estudio fue investigar la relación entre el sentido de vida y la actitud religiosa de forma transversal y correlativa. La muestra fue compuesta por 300 sujetos de ambos los sexos, $37 \%$ hombres y $63 \%$ mujeres, con edad Media de 42 años. Los instrumentos utilizados fueron la Prueba Propósito de Vida (PIL-Test), de James C. Crumbauch y Leonard T. Maholick, y la Escala de Actitud Religiosa/Espiritualidad, de Aquino. Los resultados señalan correlaciones positivas entre la actitud religiosa y la realización existencial, la actitud religiosa y la edad, la desesperación existencial y el vacío existencial y la realización existencial y la edad, habiendo también correlaciones negativas entre la actitud religiosa y la desesperación existencial, la actitud religiosa y el vacío existencial, la desesperación existencial y la realización existencial y el vacío existencial y la realización existencial. Se concluyó que la actitud religiosa es una forma de encuentro de sentido de vida así como un elemento de prevención del vacío existencial y de la desesperación existencial.

Palabras clave: Sentido de vida. Actitud. Religión. Religiosidad.

Ao longo da história da humanidade, muitas têm sido as formas pelas quais o homem tem buscado preencher a necessidade de busca de sentido. Dentre as diversas maneiras, é possível citar: a arte, a música, a ciência e a religião. O tema religiosidade - apesar de estar sendo trabalhado por autores como Antal (1981), Massimi e Mahfoud (1997) e Pintos (2007), dentre outros - tem sido pouco discutido nas Academias, por isso concebe-se que o mesmo permitiria trilhar um caminho que levasse a refletir sobre o papel da religiosidade na vida do ser humano.

A Psicologia, mesmo tendo surgido vinculada ao modelo de ciência natural, empíricobiológica, consagrou-se como a ciência que estuda o comportamento humano, e, nesse sentido, é notável que desde o início tenha se preocupado em estudar o comportamento religioso, quando ainda não se falava em espiritualidade. 
De acordo com Paiva (2005), a primeira manifestação para o estudo da espiritualidade se deu na escola de Nijmegen, na Holanda, tendo se popularizado na cultura norteamericana, a partir dos anos 60, época que coincidiu com o surgimento da Psicologia humanista, cuja idéia de espiritualidade se desvinculava da tradicional concepção de Espírito Santo e adotava a crença em um espírito humano, humanista, capaz de intuição, de afeto e de atualização de seu potencial (Rican, 2004).

Seguindo essa mesma linha de pensamento, a psicologia anglo-saxã demonstrou um verdadeiro fascínio pelo estudo empírico da espiritualidade (Paiva, 2005). Saroglou (2002), interroga se a espiritualidade não seria o sexto big factor da personalidade, enquanto Pargament (1999), sugere mudar o nome Psicologia da religião para Psicologia da espiritualidade. Segundo este autor, a espiritualidade seria a busca de sentido, de unidade e de transcendência, e a religião se definiria pelo organizacional, o ritual e o ideológico. No entanto, para ele, o pontochave dessa questão estaria no conceito de sagrado, que possibilitaria a unificação entre religião e espiritualidade, uma vez que a religião é a busca de significado pela via do sagrado e a espiritualidade, "a busca do sagrado"; assim, a espiritualidade seria a função central da religião (Pargament, 1999, como citado em Paiva, 2005).

Contrário ao pensamento de Pargament, Saroglou faz uma distinção entre espiritualidade e religião por considerar que a última se compõe de ritual, regras éticas específicas, doutrinas/crenças e aspectos emocionais. Corroborando essa idéia, Paiva, baseando-se no uso social dos termos, também diferencia Psicologia da religião de Psicologia da espiritualidade, tendo em vista que, por tradição, na cultura ocidental, a Psicologia da religião se relaciona com um ser transcendente, Deus. "Para Vergote, a Psicologia da religião não tem como objetivo o desejo de atingir uma liberdade interior e de encontrar para a vida um sentido que liberta do racionalismo estreito e das concepções tristemente utilitárias" (Paiva, 2005, p. 42).

A idéia apresentada por Vergote estaria mais próxima de uma psicologia da espiritualidade, uma vez que, historicamente, a Psicologia da religião se constitui a partir de uma visão bíblica, não tendo assimilado, até então, um objeto divino sui generis, como atualmente se verifica. Ao defender, também, a idéia de espiritualidade, Solomon especifica que a espiritualidade não necessariamente se associa à crença na existência de Deus, mas a uma atitude natural do ser humano, que se reflete no "amor bem pensado à vida", significando busca de autonomia, respeito à singularidade individual, construção pessoal, recusa da rigidez, do autoritarismo e da alienação, o que é condizente com o aprimoramento humano (Solomon, 2003, citado por Paiva, 2005). É dessa complexidade de aspectos que, segundo Amatuzi (2000), surge a idéia do homo religiosus.

Vergote define religiosidade como uma atitude perante algo ou alguém bem como uma forma de imprimir sentido aos fenômenos percebidos no mundo e em si mesmo, representada por palavras ou comportamentos expressos por meio da experiência subjetiva (Paiva, 2005). Corroborando esse pensamento, Rolo May assevera que "a atitude religiosa da pessoa reside na convicção de que há valores na existência humana dignos de que se viva e morra por eles" (May, 1991, p. 174).

\section{Visão antropológica da religião}

Só o homem dá significado às coisas e busca interpretar o mundo em que vive. A necessidade humana de dar sentido à experiência vivida é tão premente quanto suas necessidades biológicas. Sendo assim, ele é incapaz de viver em um mundo que não faça sentido (Geertz, 1989). De acordo com esse autor, nenhuma religião é apenas metafísica, 
Segundo Eliade, para se falar de experiência religiosa, é necessário entender que, para o homem religioso, existe uma distinção entre o que ele considera sagrado e o que considera profano. mas os veículos e os objetos de culto são rodeados por uma profunda seriedade moral. Em qualquer lugar, o sagrado tanto aponta a devoção como a exige, e, nesse sentido, induz a aceitação intelectual e reforça o compromisso emocional. Assim, tudo o que está além do profano constitui sérias implicações para a orientação da conduta humana, pois há uma intrínseca relação entre os aspectos metafísicos e éticos. Em todas as religiões, há uma relação significativa entre os valores de um povo e a forma como esses valores se organizam.

Segundo Eliade, para se falar de experiência religiosa, é necessário entender que, para o homem religioso, existe uma distinção entre o que ele considera sagrado e o que considera profano. Essa ruptura, de ordem qualitativa, distingue o espaço sagrado, lugar real, fonte de verdade absoluta em relação ao espaço indiscriminado, dessacralizado e neutro. É fácil, então, compreender que, para o homem religioso, o sagrado, com suas imposições e regras, tem um valor existencial, pois diz respeito à fundação ontológica de todas as coisas. Dessa forma, pode-se inferir que, nas sociedades primitivas, o homem, mediante a simbologia da sacralização dos espaços e objetos, afirmava encontrar alicerce para uma existência autêntica nas religiões (Eliade, 1999).

Segundo Geertz, na perspectiva antropológica, os valores morais e estéticos de uma cultura são resumidos no termo ethos, e os aspectos cognitivos, que elaboram a realidade, como o conceito de natureza e de sociedade, são expressos por sua "visão de mundo". Ainda de acordo com esse autor, em qualquer cultura, a religião é uma tentativa de prover significados gerais para que os sujeitos, individualmente, possam interpretar sua experiência e organizar sua conduta. Esses significados são armazenados através dos símbolos sagrados que passam a expressar, para aqueles que lhes são devotos, a forma como vêem o mundo e como devem se comportar, ou seja, os símbolos dão, ao mesmo tempo, um sentido normativo e coercitivo para a organização da vida prática, em torno dos quais a vida deve ser necessariamente vivida. Pode-se, então, afirmar que a religião é uma espécie de ciência prática que produz os valores pelos quais todos devem se guiar.

A força de uma religião em sustentar os valores sociais repousa na capacidade que seus símbolos possuam de formularem o mundo no qual esses valores são ingredientes fundamentais. Por isso, ao fundir o ethos e a "visão de mundo", a religião dá ao conjunto de valores sociais uma aparência de objetividade prática; portanto, o estudo da religião deve dar ênfase à análise das crenças e valores de um povo como conceitos destinados a trabalhar com o material simbólico. Mais recentemente, os antropólogos têm buscado no estudo dos conceitos de ethos e "visão de mundo" um arcabouço teórico mais adequado para a compreensão dos valores que possam esclarecer a regulamentação normativa dos comportamentos de pessoas reais que vivem em sociedades reais com culturas reais, buscando os seus estímulos e sua validade. O papel da antropologia, na análise dos valores religiosos de uma cultura, não é substituir a investigação filosófica, mas torná-la relevante, na exata medida em que busca fornecer uma base empírica e conceptual (Geertz, 1989).

\section{Visão psicológica da religião}

A religião tornou-se uma temática de interesse de vários ramos das ciências, incluindo a Psicologia, que, ao estudar o homem, não indaga sua opção religiosa, propondo-se apenas a compreendê-lo. De acordo com James (1902/1995, p. 16), “para o psicólogo, as tendências religiosas do homem hão de ser, pelo menos, tão interessantes quanto quaisquer outros fatores pertencentes à sua constituição mental". 
A religião como objeto de estudo da Psicologia ocorreu por volta do século XX, quando as ciências da religião (antropológicas, sociológicas, psicológicas, entre outras) começaram a florescer, e a Psicologia científica se consolidou como saber científico. No âmbito da saúde mental, por exemplo, alguns autores manifestam uma visão negativa da religiosidade, como a concepção psicanalítica de Freud (1927/1974, p. 57), que considera a atitude religiosa uma patologia ou transtorno neurótico. Segundo o autor, "...a religião seria a neurose obsessiva universal da humanidade; tal como a neurose obsessiva da criança, ela surgiu do complexo de Édipo, do relacionamento com o pai". Assim, Freud reduz o fenômeno religioso a um epifenômeno do complexo de Édipo.

Entretanto, Allport (1955/1975) considerou as idéias da psicanálise equivocadas quando concebiam a religião apenas como uma função defensiva do ego, em vez de concebê-la como núcleo integrador do desenvolvimento do ego. Já a concepção sociológica de Durkheim (1989) sobre a religião advoga que a mesma seria um sistema de mitos, dogmas, ritos e cerimônias, que tem como função ligar o homem à sociedade. Já a perspectiva da Psicologia social investiga a relação entre religião e valores (Gouveia, Clemente, \& Vidal, 1998; Urbina, Biaggio, \& Vegas, 1998).

De acordo com Massimi e Mahafoud (1997), a Psicologia da religião surge da ruptura com a tradição da Psicologia filosófica e dos conhecimentos científicos, ruptura essa essencialmente metodológica. Segundo Antal (1981), o interesse em estudar as ciências da religião emergiu em conseqüência da elaboração das chamadas Ciências do Espírito e após os conhecimentos recémadquiridos sobre os povos primitivos e as culturas tradicionais da Ásia e das Américas. Nessa perspectiva, surgem inúmeras questões sobre a religiosidade, dentre elas, a reflexão de como se dá a ligação entre Psicologia e religião.
Para responder a essa reflexão, vários pesquisadores e estudiosos investigaram o tema em questão. Antal afirma que Wundt, Külpe, Freud e James foram alguns cientistas de relevante notoriedade nesse âmbito. De maneira bem particular, esses cientistas investigaram a religião pela visão da Psicologia. Wundt acreditava que os fenômenos psíquicos são acompanhados pelos fenômenos fisiológicos, e que o fenômeno religioso deveria ser entendido na experiência coletiva, pois, para ele, a religião pertencia ao círculo dos mitos (Antal, 1981).

James (1902/1995) defendia a idéia de se estudar o fenômeno religioso a partir das manifestações individuais. Na história da Psicologia da religião, James é um marco fundamental, ao ter interpretado o fenômeno religioso pelo fluxo das emoções e sensações, tendo em vista que, até então, esses conceitos só eram estudados à luz da teologia. Külpe, por sua vez, acreditava que os fenômenos psíquicos superiores não podiam ser investigados através de métodos experimentais, e baseou-se no método da introspecção sistemática e científica aplicada aos fenômenos religiosos (Antal, 1981).

Já Freud destacou-se como grande crítico da religião, ao considerá-la uma ilusão neurótica da sociedade, e Massimi e Mahfoud (1997) acrescentam que ele era consciente de que a psicanálise não possuía subsídios suficientes para interpretar o fenômeno religioso. Jung (1958), retrocedendo à mitologia, interpretou a religiosidade como uma expressão da subjetividade humana, de caráter espiritual e universal, expresso pelo inconsciente coletivo. Pelo exposto acima, percebe-se que, sob diferentes óticas, a Psicologia, no que se refere ao tema religião/religiosidade, passou por várias crises.

Massimi e Mahfoud fazem uma reflexão quanto à nova ciência emergente sobre $\mathrm{o}$ risco de redução do objeto de estudo, visto que o tema está sendo abordado unicamente 
pelos critérios de cada ciência específica. Esse fato trouxe conseqüências para o estudo da experiência religiosa, pois reduziu o objeto à experiência humana de forma puramente emocional ou cognitiva. Uma outra questão é quanto ao método mais adequado para a investigação. No início dos estudos, usavase o método de introspecção, o que se justificava pelo fato de o objeto da Psicologia da religião ser as vivências individuais, no momento em que cada indivíduo vive sua religião.

Logo, percebe-se que houve uma evolução em relação a essa metodologia, que antes era baseada única e exclusivamente na introspecção sistemática, e hoje emprega todos os métodos considerados válidos para o estudo da religiosidade e para vários ramos da Psicologia. Tais métodos vão desde a medição das relações fisiológicas, que acompanham as atividades psíquicas, até a descrição consciente dos fenômenos religiosos vivenciados pelas pessoas, passando pela investigação dos motivos inconscientes (Antal, 1981).

Os métodos estão recentemente sendo reelaborados, principalmente no campo da neurociência, com o intuito de facilitar a expressão das vivências religiosas, sem que o sujeito examinado tenha que desenvolver conscientemente o que se passa em seu plano interior. Segundo Antal, existe certa dificuldade de se esclarecer e entender a Psicologia da religião, pois sendo o homem investigador e objeto de sua própria análise, não há como manter-se neutro em seu estudo, pois está sujeito às influências e concepções pré-estabelecidas.

\section{Atitude religiosa}

O ser humano é o único que pode conscientemente escolher o direcionamento de suas ações, tornando claras as intenções de sua essência e, através de suas atitudes, demonstrar o valor de suas palavras, o poder de seus pensamentos e o calor de seus sentimentos em tudo o que realiza. As atitudes ocupam um espaço considerável na vida, influenciando inúmeras decisões e comportamentos. E, à medida que as pessoas se relacionam com o meio social, formam atitudes em relação a esse ambiente. Para Rodrigues (2001), atitude é uma organização duradoura de crenças e cognições em geral, dotada de carga afetiva pró ou contra um objeto social definido, e que predispõe a uma ação coerente com as cognições e afetos relativos a esse objeto.

Michener, Delamater e Myers (2005) afirmam que as atitudes são constituídas de três dimensões principais: o componente cognitivo, o componente afetivo e o componente comportamental. O primeiro consiste na elaboração (pensamentos) e considera as crenças que o indivíduo têm a respeito de algo ou de alguém; o componente afetivo refere-se às emoções ou sentimentos do indivíduo, gerados a partir da experiência afetiva da situação, e, por fim, vem o componente comportamental, que está relacionado com a probabilidade ou tendência do indivíduo em comportar-se de maneira específica.

Contudo, apesar de as atitudes serem consideradas boas preditoras de comportamentos, não é seguro acreditar com total confiança que, para prever um comportamento de uma pessoa, basta conhecer suas atitudes, uma vez que, em situações concretas, nem sempre as pessoas agem de acordo com suas atitudes expressas; portanto, as atitudes envolvem o que as pessoas pensam, sentem e como elas gostariam de se comportar em relação ao objeto atitudinal. $\mathrm{O}$ comportamento não é apenas determinado pelo que as pessoas gostariam de fazer, mas também pelo que elas pensam que devem fazer, ou seja, pelas normas sociais, pelo que elas geralmente têm feito, isto é, pelos hábitos e pelas conseqüências esperadas de seu comportamento. Na verdade, o que as 
atitudes criam é um estado de predisposição à ação que, quando combinado com uma situação específica desencadeante, resulta em um comportamento (Hockenbury \& Hockenbury, 2003).

Hellern, Notaker e Gaarder (2000) afirmam que, no mundo atual, a religião ainda desempenha um papel bastante expressivo na vida social e política em todas as partes do globo, e que as maneiras de agir em relação às diversas religiões variam, podendo ser de tolerância - respeito à diferença - ou de intolerância, como resultado do conhecimento insuficiente do assunto. Para o referido autor, a religião pode ser estudada por quatro ângulos: o conceito (crença) - o aspecto intelectual da religião; cerimônia - regras predeterminadas que devem ser seguidas, ritual; organização - a irmandade entre seus seguidores e a experiência - as emoções vivenciadas nos rituais religiosos. Fazendo um paralelo com Michener et al. (2005), pode-se perceber a existência dos três componentes atitudinais: o cognitivo as crenças religiosas; o comportamental - o ritual a ser seguido, e o afetivo - as emoções vividas nos rituais.

Tomando por base a descrição do conhecimento religioso de Heller et al.(2000) e do conceito de atitude da Psicologia social, Aquino (2005) construiu um instrumento para aferir o nível de atitude religiosa de um indivíduo, que foi testado inicialmente em uma amostra de 169 estudantes universitários. Por meio de uma análise fatorial, observou que a mesma apresenta uma única dimensão, explicando $41,7 \%$ da variância total, o que indica uma coerência entre comportamentos, conhecimentos e afetos religiosos. O estudo de Panzini e Bandeira (2005), dedicado à construção e à validação de uma escala para aferir o grau em que os indivíduos utilizam a fé para lidar com eventos estressantes, demonstrou que a Escala de Atitude Religiosa apresenta forte correlação com o coping religioso-espiritual $(r=0,72 ; p<0,0001)$.

\section{Religiosidade como busca de sentido}

Albert Einstein (1981), em seu livro Como Vejo o Mundo, fez a seguinte indagação: "Tem um sentido a minha vida? A vida de um homem tem sentido? Posso responder a tais perguntas se tenho um espírito religioso" (p. 13). Na Psicologia, a logoterapia de Viktor Frankl se constituiu em uma escola de psicoterapia que se preocupou com a busca do sentido do ser humano. Ela foi considerada a terceira escola de psicoterapia de Viena - visto que a psicanálise seria primeira e a segunda, a Psicologia individual. Desde então, é uma teoria que apresenta como base três princípios: liberdade da vontade, vontade de sentido e sentido da vida.

A liberdade da vontade corresponde às possibilidades de escolha de reação diante das situações; já a vontade de sentido constitui a motivação primária do indivíduo e é inerente à condição humana; por fim, o sentido da vida corresponde a uma visão filosófica da logoterapia. Segundo essa visão, o sentido é incondicional, pessoal e situacional, i. e., muda de pessoa para pessoa e de situação para situação, manifestando-se sempre na relação Homem-Mundo (sujeito-objeto).

Frankl afirma que o homem necessita de certa tensão, pois esta implica sua saúde mental. Diferente de outras teorias, a busca de sentido não acarreta equilíbrio interior, pelo contrário, implica certo grau de tensão interna, pois é necessário que exista um sentido a ser encontrado e alguém para realizá-lo, sendo essa dinâmica chamada por Frankl de "noodinâmica". A falta de sentido, também chamada por Frankl de "vazio existencial", por si só, não ocasiona doenças, apesar de possuir esse potencial e de uma de suas possíveis conseqüências ser a neurose noogênica - o conflito do indivíduo com os seus valores (Frankl, 1990). 
"Sofrer de vida sem sentido nunca significa na realidade estar doente" (Frankl, 1990, p. 21), já que faz parte da condição humana perguntar sobre o sentido da vida. Essa sensação está sendo reforçada pelo enfraquecimento das tradições na contemporaneidade, de forma que as pessoas não sabem o que querem e o que devem fazer, o que leva o homem a querer o que os outros fazem ou a fazer o que os outros querem.

A logoterapia aproxima-se da religiosidade quando se fala em "supra-sentido". Este representa uma dimensão que explica o sofrimento além do intelecto, além da capacidade de se compreender que a vida pode ser dotada de um sentido incondicional. Sendo assim, a religiosidade pode ou não ajudar o homem no encontro de um sentido na vida, assim como nem toda crise de sentido pode ser solucionada pela crença religiosa (Frankl, 1992).

Em princípio, a logoterapia é neutra em relação ao ser religioso ou irreligioso. Para Frankl, a relação da logoterapia com a religião é mais um objeto de estudo na tentativa de compreendê-la enquanto fenômeno especificamente humano, diferentemente de outras psicoterapias que consideram a religião um mal para a humanidade. No entanto, se o paciente traz à tona a questão religiosa, o psicoterapeuta tem a obrigação de escutá-lo, não como um sacerdote, mas como alguém que se propõe ajudar o paciente de forma incondicional.

Entretanto, é preciso esclarecer que psicoterapia e religião não se encontram no mesmo nível ontológico, mas uma não anula a outra; ao contrário, elas se complementam. Assim, da mesma forma que a religião pode provocar a cura psíquica ao proporcionar bem- estar psicológico pelo alívio das aflições, a psicoterapia pode levar o paciente a reencontrar uma fonte de religiosidade inconsciente e reprimida, que vem à tona espontaneamente (Pintos, 2007).
Segundo Frankl, a logoterapia se interessa pela religião pelo simples fato de que logos significa "sentido", sendo a vontade de sentido um dos seus pilares. E qual a religião que não aponta um sentido supra-humano que transcende a nossa percepção objetiva da vida? E qual a religião que, ao apontar um sentido que ultrapassa a nossa vontade, não está impregnada de Deus?

A diferença está no fato de que a psicoterapia entende o fenômeno religioso em sentido mais amplo, no qual a religião aponta o sentido, enquanto, na logoterapia, o homem tem que encontrar o sentido, não necessariamente pela escolha de uma religião. Como diz Tillich (1996, p. 68), "ser religioso significa fazer a pergunta apaixonada pelo sentido de nossa existência". É nesse sentido que ambas, religião e logoterapia, se encontram.

Sobre esse assunto, Frankl afirma que o homem tem caminhado ao encontro de uma religiosidade pessoal, que independe de religiões, conceitos e atribuições de sagrado ao mundo, que cada indivíduo, na busca de sentido para sua existência, poderá ou não encontrá-lo na religiosidade, já que se trata de uma busca particular e única, fazendo-se mister destacar que ainda assim haverá ritos e símbolos em comum. Entretanto, em meio à diversidade e às possibilidades de sentidos existentes para cada ser humano no universo, sendo estes encontrados numa determinada religião, cada indivíduo os descobrirá na sua singularidade e individualidade, através dos seus valores atitudinais. Tendo em vista as considerações supracitadas, o objetivo do presente trabalho foi investigar a relação entre a atitude religiosa e a percepção do sentido de vida; também objetivou verificar o comportamento da atitude religiosa nas diversas fases da vida: adolescência, jovem adulto, meia idade e terceira idade. 


\section{Método}

\section{Participantes}

Foram entrevistadas 299 pessoas de Campina Grande (PB), incluindo membros da população em geral e estudantes universitários na faixa etária de 18 a 84 anos $(M=42 ; D P=16,7)$, sendo que a maioria era do sexo feminino (63\%). No que se refere ao nível de escolaridade, obteve-se $17 \%$ para o ensino fundamental, $26,3 \%$ para o ensino médio e $56,7 \%$ para o ensino superior, com os cursos completos ou incompletos. No que diz respeito ao estado civil citado pelos participantes da pesquisa, $43,3 \%$ eram solteiros, $41,3 \%$, casados, $7,7 \%$, viúvos e $7,7 \%$, separados.

Instrumentos

O Teste de Propósito de Vida (Pil-test) foi originalmente elaborado por James C. Crumbaugh e Leonard T. Maholich (Crumbaugh \& Maholich, 1964) e revisado por Harlow, Newcomb e Bentler (1987), constituindo a versão Pil-R. Essa versão apresenta três fatores: desespero existencial (alfa de Cronbach de 0,69), realização existencial (alfa de Cronbach de 0,71) e vazio existencial (alfa de Cronbach foi 0,72 ) (Aquino, 2009). Esse instrumento tem como objetivo medir o nível de realização de sentido e o vazio existencial, e consiste em 12 itens dispostos em uma escala de avaliação de 7 pontos, com os extremos $\mathbf{1}=$ discordo totalmente e $\mathbf{7}=$ concordo totalmente. Os itens dessa escala contemplam os seguintes aspectos: propósito na vida (7 itens, como, por exemplo: tenho na vida metas e objetivos muito claros); satisfação com a própria vida (6 itens, ex.: se a vida é rotineira, dolorosa, excitante, triste.); liberdade (3 itens, ex.: eu não sou uma pessoa muito responsável); medo da morte (1 item, ex.: quanto à morte, estou preparado e sem medo); idéias suicidas (1 item, ex.: quanto ao suicídio, tenho pensado seriamente ao seu respeito como uma saída); se a vida vale a pena ( 1 item, ex.: se eu morresse hoje, sentiria que minha vida foi muito valiosa). Estudos prévios indicam uma boa consistência interna, medida através de Cronbach, de 0,88 (Feldman \& Snyder, 2005).

Escala de Atitude Religiosa/Espiritualidade (Aquino, 2005). Elaborado originalmente em português, o instrumento é composto por 15 itens, distribuídos de acordo com os componentes da atitude - afetivo comportamental e cognitivo -, avaliando as atividades relacionadas aos mesmos (por exemplo, sinto-me unido a um ser maior, freqüento as celebrações de minha religião/ espiritualidade, procuro conhecer as doutrinas ou preceitos religiosos). Para respondê-lo, a pessoa deve ler cada item e indicar o valor que atribui dentro de uma escala intervalar, com os seguintes extremos: $\mathbf{1}=$ Nunca e $\mathbf{5}=$ Sempre. O estudo de Aquino (2005) indicou que a escala apresenta um único fator com uma consistência interna, verificada através do Alfa de Cronbach de 0,91.

Dados sociodemográficos. Foram acrescidas perguntas referentes à idade, ao sexo, à religião auto-atribuída e à participação em grupos religiosos.

Procedimento para a coleta dos dados

Os pesquisadores realizaram a pesquisa em duas etapas - a primeira foi efetuada de forma coletiva nas salas de aula da universidade pública de Campina Grande (PB), com estudantes universitários. A segunda etapa foi realizada de forma individual, em lugares públicos como praças, parques, etc, junto à população geral. Nesses casos, o respondente era abordado e solicitada a sua participação na pesquisa, e, quando aceito, era conduzido a um local mais reservado para responder os instrumentos. Deve-se levar em conta que esse procedimento se justifica na mediada em que se objetivou obter maior amplitude de 
idade entre os participantes da pesquisa, visto que, em geral, o ambiente universitário é predominantemente constituído por jovens.

Todos os instrumentos eram auto-explicativos, exigindo o mínimo de interferência por parte das pesquisadoras. Entretanto, todos os participantes foram instruídos em como responder os instrumentos, tendo sido explicado previamente que não havia respostas certas ou erradas e que poderiam expressar o que verdadeiramente pensavam a respeito de cada item. Apenas nos casos em que havia dificuldade de compreensão sobre algum item é que as pesquisadoras auxiliaram os respondentes, evitando-se emitir qualquer juízo opinativo.

Em todos os casos, os respondentes eram informados que respondessem de forma individual, sendo-lhes informado que suas respostas seriam confidenciais e analisadas em seu conjunto. Antes, porém, todos os participantes assinaram um Termo de Consentimento Livre e Esclarecido como uma condição para participar da pesquisa. Em média, aproximadamente 30 minutos foram suficientes para completar sua participação.

Procedimento para a análise dos dados

Tanto a tabulação dos dados como as análises estatísticas iniciais foram realizadas com o SPSS (Statistical Package for the Social Sciences) para Windows (versão 15). Esse procedimento permitiu a realização de cálculos de percentagem bem como a verificação da precisão das escalas, que foram obtidas por meio do alfa de Cronbach. Também foram utilizados cálculos de correlação de Pearson, para verificar se havia associações entre as variáveis, e uma análise de variância (ANOVA) com o Teste de Tukey para identificar onde exatamente ocorreram as diferenças do nível de religiosidade em função do ciclo da vida (adolescência, jovens adultos, meia idade e terceira idade).

\section{Resultados}

Em relação às opções religiosas, 59,3\% da amostra se autodenominou católica; 18,3\%, evangélicos; $9,7 \%$, espíritas, além de $8 \%$ que se disseram sem nenhuma religião e 4,7\% que se denominaram integrantes de outras religiões. Quanto ao grau de importância dada à religião, 5,7\% relataram nenhuma importância, 3,7\%, pouca importância, 9,7\%, média importância, 29,7\%, importância, e $51 \%$, muita importância. Dentre os respondentes, apenas 32\% afirmaram participar de algum grupo religioso.

A amostra foi classificada em quatro partes, de acordo com os períodos do ciclo da vida, seguindo a classificação proposta por Pappalia e Olds (2000), que consideram a adolescência o período que vai dos 12 aos 20 anos, jovem adulto, de 21 a 40 anos, meia-idade, 41 a 65 anos e terceira idade, 66 em diante. Assim, 43 participantes foram classificados como adolescentes, 91, como jovens adultos, 142, como de meia idade, e 23, como de terceira idade.

Como a escala Teste Propósito de Vida não é muito conhecida em um contexto brasileiro, resolveu-se realizar uma análise fatorial no conjunto dos 12 itens que compõem a escala. Inicialmente, verificou-se a adequação de se realizar uma análise fatorial, o que foi confirmado através dos índices de $\mathrm{KMO}=$ 0,85 e do Teste de Esfericidade de Bartlett, $\chi^{2}(66)=1090,5, p<0,0001$. Dessa forma, procedeu-se a uma análise fatorial dos eixos principais com rotação varimax. Assim, três componentes atenderam ao critério Kaiser, apresentando valores próprios superiores a 1, o que sugere a presença de três fatores que juntos explicam 58,84\% da variância total (Tabela 1). 
Tabela 1. Estrutura fatorial da escala propósito de vida.

\begin{tabular}{lcccc}
\hline \multicolumn{1}{c}{ Itens } & \multicolumn{5}{c}{ Fator } \\
& 1 & 2 & 3 & Geral \\
\hline 07 - Quanto a alcançar metas na vida, não & & & & \\
tenho feito nenhum progresso & $0,72^{*}$ & $-0,03$ & $-0,01$ & $0,46^{*}$ \\
04- Minha experiência pessoal é inteiramente & & & & \\
sem sentido ou propósito & $0,66^{*}$ & $-0,23$ & 0,17 & $0,66^{*}$ \\
08- Minha vida é vazia, preenchida só com desespero & $0,64^{*}$ & $-0,27$ & 0,34 & $0,75^{*}$ \\
12- Não descobri qualquer missão ou propósito na vida & $0,59^{*}$ & $-0,10$ & 0,19 & $0,55^{*}$ \\
06- Se eu pudesse escolher, nunca teria nascido & $0,54^{*}$ & $-0,22$ & $0,35^{*}$ & $0,66^{*}$ \\
01- Geralmente estou completamente aborrecido & $0,32^{*}$ & $-0,29$ & 0,25 & $0,51^{*}$ \\
03- Tenho na vida metas e objetivos muito claros & $-0,23$ & $0,69^{*}$ & 0,06 & $-0,48^{*}$ \\
02- A vida para mim parece sempre empolgante & $-0,19$ & $0,65^{*}$ & $-0,19$ & $-0,56^{*}$ \\
05- Todo dia é constantemente novo & $-0,04$ & $0,61^{*}$ & $-0,28$ & $-0,47^{*}$ \\
11- Encarar minhas tarefas diárias é uma fonte de & & & & \\
prazer e satisfação & $-0,10$ & $0,50^{*}$ & $-0,36^{*}$ & $-0,50^{*}$ \\
09- Se eu morresse hoje, sentiria que minha vida & & & & \\
foi muito valiosa & $-0,13$ & 0,21 & $-0,60^{*}$ & $-0,47^{*}$ \\
10- Quanto ao suicídio, tenho pensado seriamente & & & & \\
ao seu respeito como uma saída & 0,32 & $-0,10$ & $0,53^{*}$ & $0,51^{*}$ \\
Número de itens & 6 & 4 & 4 & 12 \\
Valores próprios & 4,3 & 1,5 & 1,1 & 4,3 \\
\% de variância explicada & 36,4 & 13,0 & 8,9 & 36,4 \\
Alfa de Cronbach & 0,78 & 0,75 & 0,65 & 0,83 \\
\hline
\end{tabular}

Notas: * [0,30] (carga fatorial mínima considerada para interpretação dos componentes). Identificação dos fatores: I= vazio existencial; II = realização existencial; III = desespero existencial.

O primeiro fator reuniu 6 itens, com saturação variando de 0,72 (quanto a alcançar metas na vida, não tenho feito nenhum progresso) a 0,32 (geralmente estou completamente aborrecido). Apresentou valor próprio de 4,3, explicando 36,4\% da variância. A consistência interna desse fator foi aferida através do alfa de Cronbach, que resultou em um coeficiente de 0,78. É plausível denominar esse fator vazio existencial.

O segundo fator agrupou 4 itens, com saturação variando de 0,69 (tenho na vida metas e objetivos muito claros) a 0,50 (encarar minhas tarefas diárias é uma fonte de prazer e satisfação). Seu valor próprio foi de 1,5, explicando 13,0\% da variância. Seu alfa de Cronbach foi de 0,75. É admissível denominá-lo realização existencial.

Por fim, o terceiro fator coligou 4 itens, com cargas fatoriais que variavam de 0,34 (minha vida é vazia, preenchida só com desespero) a -0,60 (se eu morresse hoje, sentiria que minha vida foi muito valiosa). O valor próprio foi de 1,1, e explicou 8,9\% da variância. O alfa de Cronbach foi de 0,65, e é aceitável denominá-lo desespero existencial.

Não obstante, é possível tratar a escala com apenas um único fator geral, constituída por 12 itens. Dessa forma, a sua precisão, aferida por meio do alfa de Cronbach, é de 0,83, assim, altos escores são um indicador de vazio existencial, enquanto baixos escores representam maior sensação de realização existencial. 
A segunda escala, Atitude Religiosa/Espiritualidade, embora tenha sido construída em um contexto brasileiro, ainda não é muito conhecida entre os pesquisadores da Psicologia da religião, tornandose pertinente apresentar a sua fatorabilidade. Para essa análise, foi verificada inicialmente a adequação de se realizar uma análise fatorial do conjunto de 15 itens que compõem a escala, o que foi confirmado através dos índices de $\mathrm{KMO}=0,87$ e do Teste de Esfericidade de Bartlett, $\mathrm{x}^{2}$ $(105)=1645,6, p<0,0001$. Procedeu-se, então, a uma análise fatorial considerando-a unifatorial, o que explica $38,6 \%$ da variância total (Tabela 2).

Tabela 2. Estrutura fatorial da Escala de Atitude Religiosa/Espiritualidade.

\begin{tabular}{lc}
\hline \multicolumn{1}{c}{ Itens } & Fator 1 \\
\hline 10- Freqüento as celebrações da minha religião/religiosidade & 0,77 \\
09- Participo das orações coletivas da minha religião/religiosidade & 0,77 \\
01- Leio as escrituras sagradas (Bíblia ou outro livro sagrado) & 0,68 \\
13- Extravaso a tristeza ou alegria através de músicas religiosas & 0,67 \\
08 - A religião/religiosidade influencia as minhas decisões sobre o que eu devo fazer & 0,65 \\
12- Ajo de acordo com o que a minha religião/religiosidade prescreve como correto & 0,61 \\
05- Converso com a minha família sobre assuntos religiosos & 0,60 \\
15- Quando entro numa igreja ou templo, isso me desperta emoções & 0,59 \\
06- Assisto programas de televisão sobre assuntos religiosos & 0,57 \\
02- Costumo ler livros que falam sobre religiosidade & 0,55 \\
11- Faço orações pessoais (comunicações espontâneas com Deus) & 0,55 \\
04- Participo de debates sobre assuntos que dizem respeito à religião/religiosidade & 0,47 \\
03- Procuro conhecer as doutrinas da minha religião/religiosidade & 0,43 \\
14- Sinto-me unido a um "Ser" maior & 0,39 \\
07- Converso com os meus amigos sobre as minhas experiências religiosas & 0,33 \\
Número de itens & 15 \\
Valor próprio & 5,8 \\
\% de variância explicada & 38,6 \\
Alfa de Cronbach & 0,87 \\
\hline
\end{tabular}

A escala de religiosidade reuniu 15 itens, com saturação variando de 0,77 (freqüento as celebrações da minha religião/religiosidade) a 0,33 (converso com os meus amigos sobre as minhas experiências religiosas); apresentou valor próprio de 5,8, explicando 38,6\% da variância total. A consistência interna desse componente foi aferida através do alfa de Cronbach, que resultou em 0,87 . As maiores pontuações nessa escala são o indicativo de uma elevadaa atitude religiosa.

Conhecendo a estrutura fatorial das escalas aqui utilizadas, o segundo passo foi verificar as associações entre as variáveis aqui estudadas. Assim, a Tabela 3 apresenta uma matriz correlacional entre os fatores das Escalas do Teste Propósito de Vida, da Escala de Atitude Religiosa e da idade dos participantes do estudo.

Tabela 3. Matriz correlacional.

1.Atitude religiosa

2. Vazio existencial

3. Realização existencial

4. Desespero existencial

5. Fator geral

6. idade
1

$-0,19 * * \quad 1$

$0,36 * * * \quad-0,42^{* * *} \quad 1$

$-0,26^{* * *} \quad 0,62^{* * *} \quad-0,64^{* * *} \quad 1$

$\begin{array}{lllll}-0,31 * * * & 0,87^{* * *}- & 0,78^{* * *} & 0,84 * * * & 1\end{array}$

$0,29 * * * \quad 0,19 * * \quad 0,13^{*} \quad-0,08 \quad 0,04$

1 
Embora a Tabela 3 apresente uma matriz com a associação entre todas as variáveis, aqui nos deteremos apenas nas correlações pertinentes aos objetivos do estudo. Como se pode observar, a variável atitude religiosa se correlaciona com a realização existencial $(r=0,36, p<0,0001)$. Por outro lado, a atitude religiosa se associa negativamente com o fator geral da Escala Propósito de Vida $(r=-0,31, p<0,0001)$ e positivamente com a idade $(r=0,29, p<0,0001)$. Por fim, a atitude religiosa se associou negativamente com as subescalas desespero existencial $(r=-0,26$, $p<0,0001)$ e vazio existencial $(r=-0,19, p<0,001)$.

A Figura 1 apresenta as diferenças entre os escores médios da atitude religiosa em função de quatro períodos. A adolescência apresentou a média de atitude religiosa de 44,5 ( $n=43$ ); os jovens adultos de $49,9(n=91)$; meia idade, de 50,4 $(n=142)$, e a terceira idade, de $57,4(n=23)$.

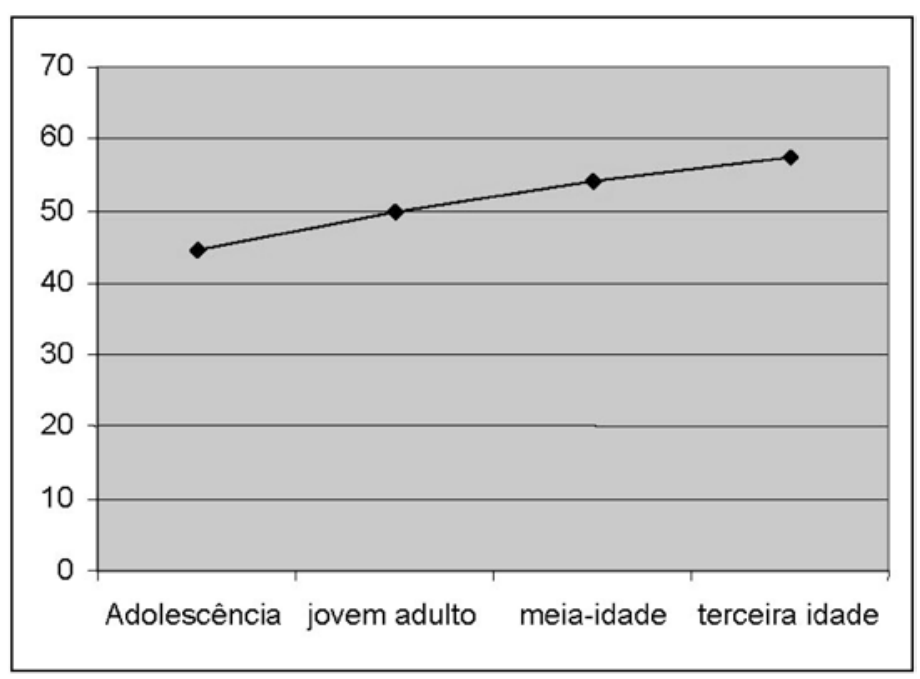

Figura 1. Atitude religiosa em função dos quatro períodos do ciclo da vida.

Uma ANOVA indicou que há diferenças entre as médias de atitude religiosa em função das etapas da vida, $F(3,0)=9,83 ; p<0,0001$, e o Teste Tukey esclarece onde ocorrem essas diferenças. Assim, há diferenças entre os grupos de adolescência e meia idade $(p<0,0001)$; adolescência e terceira idade $(p<0,0001)$, jovem adulto e meia idade $(p<0,04)$ e, por fim, jovem adulto e terceira idade $(p<0,03)$.

\section{Discussão}

Este estudo teve como objetivo conhecer as relações entre a percepção do sentido da vida e a atitude religiosa nas diversas fases da vida. Considera-se que esses objetivos foram alcançados. Entretanto, é necessário salientar as limitações da amostra investigada, que foi não-probabilistica, o que não permitiu uma generalização dos resultados encontrados. Entretanto, o propósito da pesquisa não foi esse, mas o de encontrar associações entre as variáveis propostas. Feitas essas considerações, cabe, nesta oportunidade, comentar os resultados encontrados.

No que se refere às escalas aqui utilizadas, suas validades de construtos evidenciaram bons parâmetros psicométricos. Além disso, as análises evidenciaram uma consistência interna adequada para cada subescala bem como para o fator geral. Esses resultados foram uma condição necessária para a realização do estudo correlacional, como o leitor pôde observar. 
A correlação mais forte neste estudo foi entre a atitude religiosa e a realização existencial, ou seja, quanto maior a atitude religiosa, maior a realização existencial. O desespero advém do fato de o ser humano não perceber um sentido para a sua existência; dessa forma, a atitude religiosa pode ser considerada a expressão ou o ato de possuir crença em algo superior, de forma a encontrar sentidos na vida na relação sujeito-mundo. Também a forma religiosa de estar-no-mundo, em geral, conduz a uma cosmovisão mais otimista, pela qual o homem interpreta a sua própria existência como uma missão, facilitando então a percepção de um sentido para a sua vida.

Embora Frankl (1992) tenha afirmado que o objetivo da religião é a salvação da alma e não a cura, a mesma pode, por efeito colateral, proporcionar bem-estar psicológico, pois o ser humano religioso ancora a sua existência no Absoluto. Dessa forma, pode-se interpretar que a religiosidade seja um fator de proteção do vazio e do desespero existencial. Nesse sentido, a religiosidade poderia oferecer bem-estar psíquico ao sujeito; além do mais, a religiosidade poderia ajudar o homem na busca de respostas para as suas indagações de cunho filosófico-existencial.

Isso pode ser corroborado pela correlação entre a atitude religiosa e o fator geral da Escala de Propósito da Vida. Autores como Panzini e Bandeira consideram que a religiosidade esteja associada ao bem-estar biopsíquico e emocional, voltando-se para a procura e a permanência da realização existencial dos seres humanos, evidenciandose, assim, menor probabilidade de expressarem comportamentos de risco, como o suicídio. Estudos têm mostrado que as pessoas para as quais a religiosidade está associada ao bemestar físico, psicológico e emocional têm menor probabilidade de apresentar comportamentos de risco (Panzini \& Bandeira, 2005).

Entretanto, não se pode conceber que a ausência de religiosidade deva conduzir a doenças (Frankl, 1991), mas apenas podese compreender que a religiosidade pode constituir-se apenas fator de proteção ou mesmo de enfrentamento diante das adversidades do cotidiano. Assim, a religiosidade não é uma condição necessária e nem suficiente para o bem-estar psicológico, mas pode levar a uma cosmovisão que ajuda o indivíduo a descobrir sentidos na vida.

A atitude religiosa também se correlacionou positivamente com a idade dos participantes, corroborando assim o estudo de Goldstein e Néri (1999). Segundo Amatuzzi (2000), na velhice, o lado humano coincide com a dimensão religiosa do ser, o que sugere que a religiosidade pode ter uma função integradora do self (Allport, 1955/1975; Frankl, 1992).

Os baixos escores de atitude religiosa na juventude podem ser mais bem compreendidos pelo fato de, na contemporaneidade, haver uma quebra dos valores religiosos, especialmente entre os mais jovens. Com o triunfo da ciência e da tecnologia, os valores atribuídos à religiosidade foram relegados a um segundo plano. Diante da perda dos referenciais religiosos, os indivíduos, principalmente os mais jovens, passaram a substituir seus ideais culturais pelos ideais particulares, uma vez que, nas últimas décadas, diante das múltiplas possibilidades que Ihes são oferecidas, a maioria dos jovens optam por um estilo de vida dessacralizado.

Por outro lado, os idosos são mais conscientes da finitude da vida, em comparação com os jovens, acreditando que podem encontrar na atitude religiosa uma forma de enfrentamento das questões existenciais que a morte pode suscitar no ser humano. De acordo com Geertz (1989), a atitude religiosa, nas civilizações "primitivas" e nas civilizações "modernas", especialmente entre os mais idosos, tem sido buscada com um sentido valorativo como forma de explicar e preencher o vazio que inquieta o homem, afastando deste o desespero e proporcionando-lhe a sensação de bem-estar e completude por fazê-lo sentir-se unido a um ser supremo.

Frankl (1991) considera que, para o homem antigo, a tradição era uma fonte para receber o sentido. Já nos dias atuais, com a quebra das tradições, a juventude não acolhe mais os valores que as sociedades construíram ao 
longo do tempo, o que, segundo esse autor, poderia ocasionar o vazio existencial, pois os valores apontam o dever-ser. No que diz respeito às tradições religiosas, estas poderiam não ter tanto significado para a juventude, já que existem outras formas de estar no mundo que não mais a forma sacralizada.

Em relação às correlações negativas encontradas entre a atitude religiosa e as subescalas vazio e desespero existencial, estas podem ser mais bem compreendidas segundo a teoria de Frankl (1990), que concebe que a forma religiosa de estar no mundo ajudaria o ser humano a encarar a sua própria existência com um propósito. O homem religioso encontra sentido através do seu relacionamento com um "Tu transcendente", que confere e transmite sentido à vida, i.e., como afirma Chauí - o sagrado proporciona um encantamento do mundo (Chauí, 1997).

Jung (1958) compreendia que a ausência de religião seria um dos fatores dos transtornos psíquicos. Entretanto, Frankl (1992) aventou que a religiosidade proporcionaria uma sensação de proteção e amparo, e apenas como efeito colateral proporcionaria efeitos psico-higiênicos. O homem, sendo ele religioso ou não, é um ser que busca fundamentalmente um sentido. A esse respeito, Frankl (1990) afirma ainda ser o vazio existencial o que mais atormenta as pessoas na atualidade. Dessa forma, a religiosidade pode ajudar o indivíduo a encontrar um significado único, pessoal e intransferível para sua vida, o que a protegerá contra o vazio e o desespero existencial.

\section{Considerações finais}

Uma das características do sagrado é apresentar uma cosmovisão positiva do mundo. Não obstante, com a instauração da modernidade, ocorreu a passagem do pensamento antropomórfico para as explicações naturalistas. Assim, o conhecimento científico tomou o lugar do sagrado e desencantou as explicações mágicas (Chauí, 1997). Embora a presente pesquisa não se caracterize como historiográfica, concebe-se que essas duas dimensões ainda estão presentes nas formas atuais de estar no mundo, quando se constata que a religiosidade ainda possui a função de realizar existencialmente o ser humano, servindo como fator de proteção contra o desespero e o vazio existencial. Sobretudo as pessoas mais idosas ainda estão vinculadas a uma forma de vida que inclui o sagrado em seus afetos, cognições e comportamentos.

Em conclusão, o presente estudo sugere que a atitude religiosa constitui um núcleo importante no modo de ser no mundo das pessoas investigadas nesta pesquisa, proporcionando maior sensação de valor na vida. Assim, considera-se pertinente a realização de novas pesquisas que possam compreender as funções da religiosidade no homem contemporâneo, principalmente como esta pode se relacionar com os valores humanos, as visões de morte, o bem-estar psicológico e o papel da religiosidade em pacientes com doenças crônicas ou sem possibilidades terapêuticas.

Thiago Antônio Avellar de Aquino*

Doutor em Psicologia Social - UFPB, Professor da Universidade Estadual da Paraíba

Amanda Pereira Moreira Correia. Aluna de Psicologia

Graduanda do curso de Psicologia da Universidade Estadual da Paraíba

E-mail: mandinhalfa@gmail.com

Ana Laura Câmara Marques. Aluna de Psicologia

Graduanda do curso de Psicologia da Universidade Estadual da Paraíba

E-mail: analaura_jj@hotmail.com

Cristiane Gabriel de Souza. Aluna de Psicologia

Graduanda do curso de Psicologia da Universidade Estadual da Paraíba

E-mail: cris_sje@hotmail.com 


\section{Heloísa Carolina de Assis Freitas.}

Graduanda do curso de Psicologia da Universidade Estadual da Paraíba

E-mail: heloisaaf@hotmail.com

\section{Izabela Ferreira de Araújo.}

Graduanda do curso de Psicologia da Universidade Estadual da Paraíba

E-mail: izabela_fa@hotmail.com

\section{Poliana dos Santos Dias.}

Graduanda do curso de Psicologia da Universidade Estadual da Paraíba

E-mail: poliana.s.dias@gmail.com

\section{Wilma Fernandes de Araújo.}

Graduanda do curso de Psicologia da Universidade Estadual da Paraíba

E-mail:wilmaufcg@hotmail.com

*Endereço para envio de correspondência:

Rua Mário Batista Júnior, n. 75, ap. 301 - Manaíra - João Pessoa - PB - Brasil, CEP 5043130

E-mail: logosvitae@ig.com.br

Recebido 26/03/2008 Reformulado 19/02/2009 Aprovado 26/02/2009

\section{Referências}

Allport, G. W. (1975). Desenvolvimento e personalidade. São Paulo: EPU. (Trabalho original publicado em 1955)

Amatuzzi, M. (2000). O desenvolvimento religioso: uma hipótese psicológica. Estudos de Psicologia (Campinas), 17(1), 15-30.

Antal, B. (1981). Psicologia da religião. São Paulo: Loyola.

Aquino, T. A. A. (2005). Atitude religiosa e crenças dos alunos de psicologia. Revista da Unipê, 9(1), 56-63.

Aquino, T. A. A. (2009). Atitudes e intenções de cometer suicídio: seus correlatos existenciais e normativos. Tese de Doutorado, Universidade Federal da Paraíba, João Pessoa.

Chauí, M. (1997). Convite à filosofia. São Paulo: Ática.

Crumbaugh, J. H., \& Maholich, L. T. (1964). The psychometric approach to Frankl's concept of noogênica neurosis. Journal of Clinical Psychology, 20, 200-207.

Durkheim, É. (1989). As formas elementares de vida religiosa: o sistema totêmico na Austrália (P. Neto, Trad.). São Paulo: Paulinas.

Einstein, A. (1981). Como vejo o mundo (H. P. de Andrade, Trad.). Rio de Janeiro: Nova Fronteira.

Eliade, M. (1999). O sagrado e o profano: a essência das religiões (R. Fernandes, Trad). São Paulo: Martins Fontes.

Feldman, D. B., \& Snyder, C. R. (2005). Hope and the meaningful life: Theorical and empirical associations between goaldirected thinking and life meaning. Journal Social and Clinical Psychology, 24, 401-421.

Frankl, V. E. (1990). A questão do sentido em psicoterapia (J. Mitre, Trad.). São Paulo: Papirus.

Frankl, V. E. (1991). A psicoterapia na prática (C. M. Caon, Trad.). Campinas, SP: Papirus.

Frankl, V. E. (1992). A presença ignorada de Deus (2a ed., W. O. Schlupp \& H. H. Reinhold, Trads.). São Leopoldo, RS: Sinodal; Petrópolis, RJ: Vozes.

Freud, S. (1974). O futuro de uma ilusão. In Freud, S., Edição standard brasileira das obras psicológicas completas de Sigmund Freud (Vol. 21, pp. 15-71). Rio de Janeiro: Imago. (Trabalho original publicado em 1927)

Geertz, C. (1989). A interpretação das culturas. Rio de Janeiro: LTC.

Goldstein, L., \& Néri, A. (1999). Tudo bem, graças a Deus Religiosidade e satisfação na maturidade e na velhice. In A Néri (Org.), Qualidade de vida e idade madura (pp. 109-136). Campinas, SP: Papirus.

Gouveia, V. V., Clemente, M., \& Vidal, M. A. (1998). E cuestionario de valores de Schwartz (CVS): Propuesta de adaptación en el formato de respuesta. Revista de Psicología Social, 3(13), 463-469.
Harlow, L. L., Newcomb, M. D., \& Bentler, P. M. (1987). Purpose in life test assessment using latent variable methods. British Journal of Clinical Psychology, 26, 235-236.

Hellern, V., Notaker, H., \& Gaarder, G. (2000). O livro das religiốes (I. M. Lando, Trad.). São Paulo: Cia. das Letras.

Hockenbury, D. H., \& Hockenbury, S. E. (2003). Descobrindo a psicologia. São Paulo: Manole.

James, W. (1995). As variedades da experiência religiosa: um estudo sobre a natureza humana. São Paulo: Cultrix. (Trabalho original publicado em 1902)

Jung, C. G. (1958). Psycologie et réligion. Paris: Buchet/Córrea

Massimi, M. \& Mahfoud, M. (1997). Abordagens psicológicas à experiência religiosa: traçando a história. In Anais do Seminário A Psicologia e o Senso Religioso (pp. 43-57). Ribeirão Preto, SP: Salus.

May, R. (1991). O homem à procura de si mesmo (17a ed.). Petrópolis, RJ: Vozes.

Michener, H. A. H., Delamater, J. D., \& Myers, J. D. (2005) Psicologia social. Śão Paulo: Thomson.

Paiva, G. J. (2005). Psicologia da religião, psicologia da espiritualidade: oscilações conceituais de uma (?) disciplina. In M. M. Amatuzzi (Org.), Psicologia e espiritualidade (pp. 31-47). São Paulo: Paulus.

Pargament, K. I. (1999). The psychology of religion and spirituality? Yes and no. Internacional Journal for the Psychology of Religion, 9, 3-16.

Panzini, R. G., \& Bandeira. D. R. (2005). Escala Dd coping religiosoespiritual (Escala Cre1): elaboracão e validação de construto. Psicologia em Estudo, 10(3), 507-516.

Pappalia, D. E., \& Olds, S. W. (2000). Desenvolvimento humano (D. Bueno, Trad.). Porto Alegre: Artmed.

Pintos, C. G. (2007). Un hombre llamado Viktor. Buenos Aires: San Pablo.

Rican, P. (2004). Spirituality: The story of a concept in the psychology of religion. Archiv fur Religionspsychologie, 26, 135-156.

Rodrigues, A. (2001). Psicologia social. Petrópolis, RJ: Vozes.

Saroglou, V. (2002). Religion and the five factors of personality: A meta-analytic review. Personality and Individual Differences, $32,15-25$.

Tillich, P. (1996). Dinâmica da fé. São Leopoldo, RS: Sinodal.

Urbina, C. I., Biaggio, A., \& Vegas, C. (1998). Relações entre julgamento moral pós-convencional, grau de fé, afiliação religiosa e participação religiosa. In M. L. S. Moura, J. C. A. Spinillo (Orgs.), Pesquisa brasileira em psicologia do desenvolvimento (pp. 36-48). Rio de Janeiro: Editora da UERJ. 